\title{
Prediction of postoperative refractive astigmatism before toric intraocular lens implantation
}

\author{
Atsushi Kawahara
}

\begin{abstract}
Background: To determine the preoperative factors influencing refractive astigmatism after cataract surgery for astigmatism correction by toric intraocular lens $(\mathrm{IOL})$ implantation and to evaluate the prediction model using these factors.

Methods: Prospective, observational case series. The right eyes of forty consecutive patients with preoperative corneal astigmatism of the total cornea of 1.5 diopters (D) or more in magnitude and scheduled for implantation of a non-toric IOL during cataract surgery with a 2.4-mm temporal clear corneal incision were examined prospectively. The vertical/horizontal astigmatism component (JO) and oblique astigmatism component (J45) of refractive and corneal astigmatism were converted using power vector analysis. Multivariate regression analysis was performed with refractive astigmatism at three months postoperatively as the dependent variable, and preoperative parameters including age, sex, refractive astigmatism, corneal astigmatism, sphere, spherical equivalent, intraocular pressure, corneal thickness, anterior chamber depth, lens thickness, lens positions (tilt and decentration), axial length, and corneal higher order aberrations as independent variables. The root mean square (RMS) errors were calculated to express the regression model fit.
\end{abstract}

Results: The regression model for the $\mathrm{J} 0$ component was Postoperative refractive $\mathrm{J} 0=1.05 \times$ Coneal $\mathrm{J} 0-0.14$ $\left(R^{2}=0.96, P<0.001\right)$. The model for the $J 45$ component was Postoperative refractive $J 45=0.68 \times$ Coneal $J 45+0.1$ $9 \times$ Preoperative refractive $\mathrm{J45}-0.06\left(R^{2}=0.72, P<0.001\right)$. The mean RMS errors for preoperative corneal astigmatism alone and the multivariate model were $0.58 \mathrm{D}$ and $0.46 \mathrm{D}$, respectively. There was a statistically significant difference between them $(P=0.02)$.

Conclusions: Refractive astigmatism after implantation of a toric $\mathrm{IOL}$ can be predicted by the regression model more accurately than by corneal astigmatism alone. However, the prediction of oblique astigmatism remains a challenge.

Keywords: Astigmatism, Refractive astigmatism, Corneal astigmatism, Toric intraocular lens, Cataract surgery

\section{Background}

In recent years, the goal of cataract surgery has shifted from improving postoperative corrected visual acuity to improving postoperative uncorrected visual acuity. In order to achieve this goal, it is necessary to eliminate

Correspondence: atsusi-k@coral.plala.or.jp

San Ai Eye Clinic, 1-3-28, Yamauchi, Okinawa, Japan postoperative residual astigmatism, and a toric intraocular lens (IOL) has become widely used. The correction of astigmatism with toric IOLs is based on the assumption that all astigmatism originates from the cornea and lens. However, it is known that the difference between postoperative refractive and corneal astigmatism is not nil $[1,2]$. Postoperative refractive astigmatism is thought

(c) The Author(s). 2021 Open Access This article is licensed under a Creative Commons Attribution 4.0 International License, which permits use, sharing, adaptation, distribution and reproduction in any medium or format, as long as you give appropriate credit to the original author(s) and the source, provide a link to the Creative Commons licence, and indicate if changes were made. The images or other third party material in this article are included in the article's Creative Commons licence, unless indicated otherwise in a credit line to the material. If material is not included in the article's Creative Commons licence and your intended use is not permitted by statutory regulation or exceeds the permitted use, you will need to obtain permission directly from the copyright holder. To view a copy of this licence, visit http://creativecommons.org/licenses/by/4.0/ The Creative Commons Public Domain Dedication waiver (http://creativecommons.org/publicdomain/zero/1.0/) applies to the data made available in this article, unless otherwise stated in a credit line to the data. 
to include lens capsule (and/or IOL) tilt and decentration, and unknown ocular components in addition to corneal astigmatism. Therefore, it is necessary to reconsider which parameters predict postoperative refractive astigmatism in eyes indicated for toric IOLs.

Three observational studies showed that postoperative refractive and preoperative corneal astigmatism had a significant correlation in pseudophakic eyes with non-toric IOLs, and preoperative corneal astigmatism was the most significant predictor in multivariate regression analysis [3-5]. However, their correlations were assessed without considering the power of corneal astigmatism. The purpose of our study was to determine the predictors of postoperative refractive astigmatism in eyes with corneal astigmatism before cataract surgery for astigmatism correction by toric IOL implantation. To our knowledge, this study is the first study to assess the correlation between postoperative refractive astigmatism and preoperative parameters in pseudophakic eyes with non-toric IOLs, including the eye with an indication of toric IOL implantation.

\section{Methods \\ Subjects}

Consecutive patients who were scheduled for routine cataract surgery at the San Ai Eye Clinic between October 1, 2019 and September 30, 2020 were screened for possible inclusion in the study. The inclusion criteria were right eyes with preoperative total corneal astigmatism of 1.5 diopters (D) or more in magnitude and scheduled for phacoemulsification with implantation of non-toric IOLs. The exclusion criteria were eyes with any pathology of the cornea, optic nerve or macula; eyes with a lens nucleus harder than grade 4 [6]; eyes with poor mydriasis $(<$ $4.5 \mathrm{~mm}$ ); eyes with a possible zonular dehiscence or pseudoexfoliation; eyes with a history of surgery or inflammation; and patients who wanted implantation of toric IOLs.

After topical anesthesia with $4 \%$ lidocaine hydrochloride, coaxial phacoemulsification was performed through a $2.4 \mathrm{~mm}$ temporal clear corneal single-plane incision at the 9 o'clock position in the right eye. A side-port incision also created with the left hand in a forearm position comfortable for a right-handed surgeon. Single-piece acrylic non-toric IOLs were implanted in the capsular bag through an unenlarged temporal incision. All incisions were hydrated to aid closure of the incision. No eye required sutures. Spherical equivalent (SE) power of the IOL meeting the focal distance desired by the patient (emmetropia or mild myopia) was calculated preoperatively using the SRK/T formula. Two surgeons (AK and DK) performed all cataract surgeries.

\section{Outcome Measures}

Except for the examining equipments and the timing of the examinations, we performed the same as in the previous study [3]. All eligible patients underwent ocular examinations preoperatively and at three months postoperatively, and data for corrected distance visual acuity (CDVA), refractive astigmatism, corneal astigmatism (total corneal astigmatism), sphere, SE, intraocular pressure (IOP), corneal thickness, anterior chamber depth, lens thickness, lens positions (tilt and decentration), axial length, and corneal higher order aberrations (HOAs) were collected. CDVA was examined using decimal charts, and this was converted to the logarithm of minimal angle of resolution (logMAR) scale. Objective refraction was measured using an autokerato/refractometer (ARK530 A; Nidek, Gamagori, Japan). SE value was determined as the sum of the spherical power and half of the cylindrical power. IOP was measured using a non-contact tonometer (NT-4000; Nidek). Corneal astigmatism, corneal thickness, anterior chamber depth, lens thickness, lens positions (tilt and decentration), and corneal HOAs were examined using a swept-source optical coherence tomography (OCT; CASI A2, Tomey, Nagoya, Japan). The CASIA2 performs a threedimensional analysis with sixteen different angles of anterior-segment OCT images and then automatically produces the measurements. The degree of lens tilt and decentration was evaluated in absolute values relative to the visual axis. Corneal HOAs were calculated by Fourier harmonic transformation. The refractive powers of the total cornea are transformed into four trigonometric components: the SE power, the first-order asymmetry, the secondorder regular astigmatism, and the third and higher order irregularity. The asymmetry and third and higher order irregularity are defined as HOAs [7]. The repeatability and reproducibility of these corneal and anterior segment measurements were confirmed [8]. Axial length was measured using the IOLMaster 500 (Carl Zeiss Meditec AG, Jena, Germany) biometry. Information on age and sex were also extracted preoperatively.

Refractive and corneal astigmatism were expressed as a negative value and their values were converted to power vector components as described by Thibos et al. [9]. This analysis expresses the vertical $\left(90^{\circ}\right) /$ horizontal $\left(180^{\circ}\right)$ astigmatism component as $\mathrm{J} 0$, and the oblique astigmatism component $\left(45^{\circ}\right.$ and $\left.135^{\circ}\right)$ as $J 45$. Manifest refractions in conventional script notation (Sphere, $\mathrm{Cy}$ linder $\times$ Axis) were converted to power vectors by the following formulas:

$$
\begin{aligned}
& J 0=-(\text { Cylinder } / 2) \times \cos (2 \times \text { Axis }) \\
& J 45=-(\text { Cylinder } / 2) \times \sin (2 \times \text { Axis })
\end{aligned}
$$

In this representation, as astigmatism is represented in rectangular vector form, conventional scalar methods can be applied to each vector component, which simplifies the mathematical and statistical analysis of astigmatism. 


\section{Statistical analysis}

Statistical analysis was performed in much the same way as in the previous study [3]. Predictions of the postoperative refractive astigmatic components (J0 and J45) were determined by multivariate linear regression analysis. Multivariate regression analysis was performed with postoperative refractive J0 and J45 as the dependent variable, and preoperative parameters including age, sex, refractive J0 and J45, corneal J0 and $\mathrm{J45}$, sphere, SE, IOP, corneal thickness, anterior chamber depth, lens thickness, lens positions (tilt and decentration), axial length, and corneal HOAs as independent variables. In the multivariate analysis, variables with a partial regression coefficient of $\mathrm{P}$ value > 0.10 were removed using the stepwise method. Variance inflation factors were calculated to assess multicollinearity. Variables with a variance inflation factor of more than ten were considered to have excessive collinearity and were excluded. Residual errors, which were differences between the measured and predicted values in the regression analysis of postoperative refractive J0 and J45, were also calculated. For residual analysis, independence of residual errors was assessed using the Durbin-Watson statistic, and heteroscedasticity was assessed using the Breusch-Pagan test. A Durbin-Watson statistic in the range of one and a half to two and a half indicates independence. Data were analyzed with BellCurve for Excel, version 3.21 (Social Survey Research Information Co., Ltd., Tokyo, Japan), with a $\mathrm{P}$ value $<0.05$ considered statistically significant.

The root mean square (RMS) error was calculated to express the regression model fit in the familiar unit of diopters. The RMS error for each eye was as follows:
RMS error $=2 \times \sqrt{\left(J 0_{\text {Measured }}-J 0_{\text {Predicted }}\right)^{2}+\left(\left(J 45_{\text {Measured }}-J 45_{\text {Predicted }}\right)\right)^{2}}$

The RMS error is appropriate for assessing standard least squares regression, which minimizes the squared error. Comparison of the RMS errors between preoperative corneal astigmatism alone and the multivariate model were performed using the Mann-Whitney $\mathrm{U}$ test.

\section{Results}

All forty enrolled eyes completed the scheduled examinations. No eye had any perioperative complications. Table 1 shows the mean refractive and corneal astigmatism. The mean vector of preoperative and postoperative refractive astigmatism, and preoperative and postoperative corneal astigmatism was $1.24 \mathrm{D}$ axis $180.0^{\circ}, 0.89 \mathrm{D}$ axis $0.0^{\circ}, 0.59 \mathrm{D}$ axis $180.0^{\circ}$, and $0.54 \mathrm{D}$ axis $180.0^{\circ}$, respectively. For both refractive and corneal astigmatism, the mean of the absolute values of $\mathrm{J} 0$ is larger than the mean of the absolute values of $\mathbf{5 4 5}$, indicating less oblique astigmatism. The magnitude of corneal astigmatism was virtually unchanged between pre- and post-operatively, and refractive astigmatism was reduced, indicating that cataract surgery had eliminated lens astigmatism. Table 2 shows the variables for multivariate analysis other than astigmatism, although CDVA is not an independent variable.

After a stepwise multivariable regression analysis in postoperative refractive $\mathrm{J}$, preoperative corneal $\mathrm{J} 0$ was found to be an independent significant predictor (Table 3). The regression equation of postoperative refractive J0 was as follows:

Table 1 Refractive and corneal astigmatism

\begin{tabular}{|c|c|c|c|c|}
\hline & \multicolumn{2}{|l|}{ Preoperative } & \multicolumn{2}{|c|}{ Postoperative } \\
\hline & Mean \pm SD & Range & Mean \pm SD & Range \\
\hline Refractive astigmatism (D) & $-2.42 \pm 1.09$ & $-5.50--0.75$ & $-2.01 \pm 0.86$ & $-5.00--1.00$ \\
\hline J0 component (D) & $-0.62 \pm 1.10$ & $-2.55-1.62$ & $-0.44 \pm 0.94$ & $-2.49-1.37$ \\
\hline (The absolute value) & $(1.11 \pm 0.59)$ & $(0.12-2.55)$ & $(0.93 \pm 0.48)$ & $(0.09-2.49)$ \\
\hline J45 component (D) & $0.04 \pm 0.41$ & $-1.03-1.15$ & $-0.03 \pm 0.32$ & $-0.86-0.49$ \\
\hline (The absolute value) & $(0.31 \pm 0.28)$ & $(0.00-1.15)$ & $(0.26 \pm 0.19)$ & $(0.00-0.86)$ \\
\hline Corneal astigmatism $(\mathrm{D})^{*}$ & $-1.88 \pm 0.57$ & $-4.40--1.50$ & $-1.79 \pm 0.72$ & $-4.30--0.90$ \\
\hline J0 component (D) & $-0.29 \pm 0.88$ & $-2.18-1.18$ & $-0.27 \pm 0.87$ & $-2.14-1.20$ \\
\hline (The absolute value) & $(0.86 \pm 0.34)$ & $(0.21-2.18)$ & $(0.82 \pm 0.40)$ & $(0.03-2.14)$ \\
\hline J45 component (D) & $0.03 \pm 0.31$ & $-0.52-0.72$ & $0.01 \pm 0.31$ & $-0.63-0.62$ \\
\hline (The absolute value) & $(0.26 \pm 0.18)$ & $(0.00-0.72)$ & $(0.26 \pm 0.17)$ & $(0.00-0.63)$ \\
\hline
\end{tabular}

$D$ diopter, $J 0$ vertical/horizontal astigmatism component, $J 45$ oblique astigmatism component

*Corneal astigmatism of the total cornea 
Table 2 Patient characteristics and measurements

\begin{tabular}{|c|c|c|c|c|}
\hline \multirow[t]{2}{*}{ Parameter } & \multicolumn{2}{|l|}{ Preoperative } & \multicolumn{2}{|c|}{ Postoperative } \\
\hline & Mean \pm SD & Range & Mean \pm SD & Range \\
\hline CDVA (logMAR) & $0.14 \pm 0.15$ & $-0.18-0.52$ & $-0.10 \pm 0.07$ & $-0.18-0.10$ \\
\hline Age (years) & $70.9 \pm 8.8$ & $46-87$ & & \\
\hline Sex (men/women) & $21 / 19$ & & & \\
\hline Sphere (D) & $0.65 \pm 3.79$ & $-18.25-5.25$ & $0.49 \pm 0.92$ & $-2.50-2.25$ \\
\hline SE (D) & $-0.56 \pm 3.80$ & $-19.50-3.75$ & $-0.52 \pm 0.85$ & $-3.13-0.38$ \\
\hline IOP (mmHg) & $14.8 \pm 2.6$ & $10.0-22.0$ & $12.8 \pm 3.0$ & 7.0-21.0 \\
\hline Corneal thickness $(\mu \mathrm{m})$ & $532 \pm 32$ & $468-606$ & $533 \pm 32$ & $470-607$ \\
\hline Anterior chamber depth (mm) & $2.65 \pm 0.46$ & $1.46-3.41$ & $4.24 \pm 0.30$ & $3.47-4.81$ \\
\hline Lens thickness (mm) & $4.65 \pm 0.36$ & $3.62-5.36$ & & \\
\hline Lens tilt (degree) & $4.58 \pm 1.34$ & $0.80-6.90$ & & \\
\hline Lens decentration (mm) & $0.15 \pm 0.08$ & $0.03-0.32$ & & \\
\hline Axial length (mm) & $23.79 \pm 1.53$ & $21.44-29.67$ & $23.70 \pm 1.53$ & $21.35-29.57$ \\
\hline Corneal HOAs $(\mu \mathrm{m})$ & $0.27 \pm 0.08$ & $0.15-0.56$ & $0.27 \pm 0.07$ & $0.14-0.49$ \\
\hline
\end{tabular}

CDVA corrected distance visual acuity, logMAR logarithm of minimal angle of resolution, $D$ diopter, SE spherical equivalent, IOP intraocular pressure, HOAs higher order aberrations

Posoperative J0 $=1.05 \times$ Coneal J0-0.14 $\left(R^{2}=0.96, P<0.001\right)$

In postoperative refractive J45, preoperative corneal and refractive $\mathbf{5} 45$ were found to be independent predictors (Table 4). The regression equation of postoperative refractive J45 was as follows:

Postoperative J45 $=0.68 \times$ Coneal $J 45+0.19$

$$
\begin{aligned}
& \times \text { Preoperative refractive J45-0.06 } \\
& \left(R^{2}=0.72, P<0.001\right)
\end{aligned}
$$

There were no problems in either multicollinearity or residual analysis in both regression equations.

The mean RMS errors for preoperative corneal astigmatism alone and the multivariate models were $0.58 \pm$ $0.25 \mathrm{D}$ and $0.46 \pm 0.25 \mathrm{D}$, respectively. The mean RMS error of the multivariate model was statistically significantly lower than that of corneal astigmatism alone $(P=$ 0.02).

\section{Discussion}

Multivariate regression analysis revealed that preoperative astigmatism was significantly correlated with

Table 3 Multivariate regression analysis of postoperative refractive $\mathrm{J0}$

\begin{tabular}{llll}
\hline $\begin{array}{l}\text { Preoperative } \\
\text { parameter }\end{array}$ & $\begin{array}{l}\text { Partial regression } \\
\text { coefficient }\end{array}$ & $\begin{array}{l}\text { Standard partial } \\
\text { regression coefficient }\end{array}$ & P value \\
\hline Corneal J0 & 1.05 & 0.98 & $<0.001$ \\
Intercept & -0.14 & & $<0.001$ \\
\hline
\end{tabular}

$\mathrm{J} 0=$ vertical/horizontal astigmatism component

$\mathrm{R}^{2}=0.96, \mathrm{P}<0.001$ postoperative refractive astigmatism in both the vertical/ horizontal and oblique components. In the respective multivariate regression analyses, the standard partial regression coefficients of preoperative corneal astigmatism gave the large and maximum absolute values. The standard partial regression coefficients describe what the partial regression coefficients would equal if all variables had the same standard deviation. The magnitude of the standard partial regression coefficients shows the relative importance of different variables. These results suggest that preoperative corneal astigmatism is the most significant predictor of postoperative refractive astigmatism. In terms of $\mathrm{R}^{2}$ values, preoperative corneal astigmatism was largely predictive of postoperative refractive vertical/ horizontal astigmatism. As for the oblique astigmatism, preoperative corneal and refractive astigmatism predicted postoperative refractive oblique astigmatism. It is possible that both refractive and corneal astigmatism should be considered when predicting postoperative refractive astigmatism as refractive astigmatism may contain real, independent information about both the

Table 4 Multivariate regression analysis of postoperative refractive $\mathbf{4 5}$

\begin{tabular}{llll}
\hline $\begin{array}{l}\text { Preoperative } \\
\text { parameter }\end{array}$ & $\begin{array}{l}\text { Partial regression } \\
\text { coefficient }\end{array}$ & $\begin{array}{l}\text { Standard partial } \\
\text { regression } \\
\text { coefficient }\end{array}$ & P value \\
\hline Corneal J45 & 0.68 & 0.66 & $<0.001$ \\
Refractive J45 & 0.19 & 0.25 & 0.045 \\
Intercept & -0.06 & & 0.057
\end{tabular}

$\mathrm{J45}=$ oblique astigmatism component $R^{2}=0.72, P<0.001$ 
anterior and posterior cornea not reflected in keratometry. However, the $\mathrm{R}^{2}$ value of the oblique astigmatism was less than the vertical/horizontal astigmatism. Taken together, the findings of the current study demonstrated that corneal astigmatism is the most significant predictor of postoperative refractive astigmatism, even in eyes with a corneal astigmatic error, and postoperative with-therule or against-the-rule refractive astigmatism can be independently predicted using corneal astigmatism, although the prediction of oblique astigmatism remains a challenge.

Observational studies demonstrated that preoperative corneal astigmatism was the most significant predictor in multivariate regression analysis, although the power of corneal astigmatism was not considered [3-5]. In addition, Leffler et al. reported that refractive astigmatism after cataract surgery and preoperative corneal astigmatism were correlated ( $R^{2}$ values: 0.51 and 0.05 for J0 and J45, respectively) [4]. Similar results have been addressed elsewhere $[3,5]$. In contrast, the present study demonstrated that postoperative refractive and preoperative corneal and refractive astigmatism had a better correlation ( $R^{2}$ values: 0.96 and 0.72 for J0 and J45, respectively). This was probably due to the smaller incision width and/or the evaluation of the total cornea using swept-source anterior-segment OCT in our study. The regression equations obtained in this study allows the refractive astigmatism after cataract surgery to be estimated. Toric IOL power could subsequently be derived by transformation from the refractive to the IOL plane. These findings should be applicable to left eyes, although only right eyes were analyzed in this study. The reason for this is that refractive astigmatism [10-12], corneal curvature [13-16], and pupil center [17] demonstrate mirror interocular symmetry about the mid-sagittal plane. Further, the multivariate models improved the RMS error using only corneal astigmatism. Accordingly, we believe that it is appropriate to use the regression model for evaluation prior to cataract surgery using toric IOL implantation.

A potential limitation of the present study is the small number of cases. However, there is no statistical problem as multivariate linear regression equations in this study have one or two independent variables [18]. On the other hand, a larger number of cases would be needed to improve the accuracy of the regression model.

\section{Conclusions}

This study showed that corneal astigmatism is the strongest correlate of postoperative refractive astigmatism in eyes with an indication of toric IOL implantation, but that refractive astigmatism can be predicted by the regression equation more accurately than by preoperative corneal astigmatism alone. However, the oblique astigmatism was not yet fully predicted. These findings added new insights to the prediction of postoperative astigmatism before toric IOL implantation, but further studies are needed to provide better predictions, especially in terms of oblique astigmatism.

\section{Abbreviations \\ IOL: Intraocular lens; D: Diopters; SE: Spherical equivalent; CDVA: Corrected distance visual acuity; IOP: Intraocular pressure; HOAs: Higher order aberrations; logMAR: Logarithm of minimal angle of resolution; OCT: Optical coherence tomography; J0: Vertical/horizontal astigmatism component; J45: Oblique astigmatism component; RMS: Root mean square}

\section{Acknowledgements \\ I would like to thank Daisaku Kashimoto for his contribution to this paper.}

\section{Author's contributions}

AK: study conception, study design, data acquisition, data analysis/ interpretation of data, and drafting and revising of work. The author read and approved the final manuscript.

Funding

Not applicable.

\section{Availability of data and materials}

The datasets used and analyzed for the present study can be obtained from the corresponding author on reasonable request.

\section{Declarations}

\section{Ethics approval and consent to participate}

This study was approved by the Tokushukai Group Ethics Committee. Tenets of declaration of Helsinki were followed, and written informed consent was obtained from all subjects.

\section{Consent for publication}

Not applicable.

\section{Competing interests}

The author declares no competing interests regarding the publication of this paper.

Received: 16 February 2021 Accepted: 21 April 2021

Published online: 08 May 2021

References

1. Seo KY, Yang H, Kim WK, et al. Calculations of actual corneal astigmatism using total corneal refractive power before and after myopic keratorefractive surgery. PLoS One 2017;12:e0175268.

2. Holladay JT, Hill WE, Steinmueller A. Corneal power measurements using scheimpflug imaging in eyes with prior corneal refractive surgery. J Refract Surg 2009;25:862-8.

3. Kawahara A, Sato T, Hayashi K. Multivariate Regression Analysis to Predict Postoperative Refractive Astigmatism in Cataract Surgery. J Ophthalmol 2020;2020:9842803.

4. Leffler $C T$, Javey $G$, Mahmood MA. Prediction of postoperative astigmatism in cataract surgery. Can J Ophthalmol 2008:43:551-4.

5. Kawahara A, Takayanagi Y. Comparison of refractive and keratometric astigmatism after microincision cataract surgery. J Cataract Refract Surg 2017:43:1050-3.

6. Chylack LT, Wolfe JK, Singer DM, et al. The lens opacities classification system. The longitudinal study of cataract study group. Arch Ophthalmol 1993;111:831-6.

7. Hayashi K, Ogawa S, Yoshida M, et al. Wound stability and surgically induced corneal astigmatism after transconjunctival single-plane sclerocorneal incision cataract surgery. Jpn J Ophthalmol 2017;61:113-23.

8. Hoffmann PC, Abraham M, Hirnschall N, et al. Prediction of residual astigmatism after cataract surgery using swept source fourier domain optical coherence tomography. Curr Eye Res 2014;39:1178-86. 
9. Thibos $L N$, Wheeler W, Horner D. Power vectors: an application of Fourier analysis to the description and statistical analysis of refractive error. Optom Vis Sci 1997;74:367-75.

10. Kelly JE, Mihashi T, Howland HC. Compensation of corneal horizontal/ vertical astigmatism, lateral coma, and spherical aberration by internal optics of the eye. J Vis 2004:4:262-71.

11. Guggenheim JA, Zayats T, Prashar A, et al. Axes of astigmatism in fellow eyes show mirror rather than direct symmetry. Ophthalmic Physiol Opt 2008:28:327-33.

12. Leffler $C T$, Wilkes $M$, Reeves J, et al. Postoperative astigmatism in the second eye undergoing cataract surgery. Arch Ophthalmol 2011;129:295-300.

13. Boote $\mathrm{C}$, Hayes $\mathrm{S}$, Abahussin $\mathrm{M}$, et al. Mapping collagen organization in the human cornea: left and right eyes are structurally distinct. Invest Ophthalmol Vis Sci 2006;47:901-8.

14. Myrowitz EH, Kouzis AC, O'Brien TP. High interocular corneal symmetry in average simulated keratometry, central corneal thickness, and posterior elevation. Optom Vis Sci 2005;82:428-31.

15. Read SA,Collins MJ,Carney LG. The influence of eyelid morphology on normal corneal shape. Invest Ophthalmol Vis Sci 2007;48:112-9.

16. Mission GP. Circular polarization biomicroscopy: a method for determining human corneal stromal lamellar organization in vivo. Ophthalmic Physiol Opt 2007:27:256-64.

17. Lu F, Wu JX, Qu J, et al. Association between offset of the pupil center from the corneal vertex and wavefront aberration. J Optom 2008;1:8-13.

18. Harrell FE Jr. Regression Modeling Strategies; With Applications to Linear Models, Logistic Regression, and Survival Analysis. Springer-Verlag New York, 2001.

\section{Publisher's Note}

Springer Nature remains neutral with regard to jurisdictional claims in published maps and institutional affiliations.

Ready to submit your research? Choose BMC and benefit from:

- fast, convenient online submission

- thorough peer review by experienced researchers in your field

- rapid publication on acceptance

- support for research data, including large and complex data types

- gold Open Access which fosters wider collaboration and increased citations

- maximum visibility for your research: over $100 \mathrm{M}$ website views per year

At BMC, research is always in progress.

Learn more biomedcentral.com/submissions 